\title{
SELECTED INFECTIOUS DISEASE DISASTERS FOR NURSING STAFF TRAINING AT EGYPTIAN EASTERN BORDER

\author{
By
}

MAMDOUH M. EL-BAHNASAWY ${ }^{1}$, NARGIS ALBERT LABIB ${ }^{2}$, MAGDA ABDEL HAMEED ABDEL-FATTAH ${ }^{3}$, ABEER MOHAMMAD ABDALLAH IBRAHIM $^{4}$ AND TOSSON A. MORSY ${ }^{5}$

\author{
Military Medical Academy ${ }^{1,4}$, Departments of Public Health ${ }^{2}$, Nursing \\ Administration $^{3}$, and Parasitology ${ }^{5}$, Faculties of Medicine ${ }^{2,4}$ and Nursing ${ }^{3}$, Cairo \\ University ${ }^{2,3}$, and Ain Shams University, Cairo $11566^{5}$, Egypt
}

\begin{abstract}
Infectious disease disasters are events that involve a biological agent, disease and that result in mass casualties, such as a bioterrorism attack, an emerging outbreak of infectious disease; all disasters pose a risk of infection transmission. But, infectious disease disasters pose the great-risk to illness or death from an infectious disease. This study raised the awareness and improved knowledge by educational program for Military Nursing Staff on selected infectious disease disasters acquired at Egyptian Eastern Border. The selected arthropod-borne diseases were Anthrax, Tick borne relapsing, Louse borne replasing fever and liver fluke; Clonorchis sinensis. An interventional study was used, for 125 staff nurse who accepted to participate. The tools dealt with four questionnaires: (1) Some sociodemographic characteristics data (2) Educational needs assessment a structured questionnaire. (3) Knowledge test (pre/ post-test) and (4) Participants' reactions questionnaire.

The results showed that educational intervention significantly improvements the nursing staff knowledge, which were achieved at the immediate post intervention phase, and retained via three months post-test phase. In the service training programs about infectious disease disasters at Egyptian Eastern Border must be established and continued on regular basis. This would improve their knowledge about the epidemiology of these infectious disease disasters.
\end{abstract}

Key words: Military Nursing Staff, Infectious Disease, Disasters, Egyptian Eastern Border

\section{Introduction}

The geographical location of Egypt is: northern Africa, bordering the Mediterranean Sea, between Libya and the Gaza strip, and the red sea north of Sudan, and includes the Asian Sinai Peninsula, controls Sinai Peninsula, only land bridge between Africa and remainder of Eastern hemisphere, controls Suez canal a sea link between Indian ocean and Mediterranean sea, size, and juxtaposition to Israel, establish its major role in Middle Eastern geopolitics, dependence on upstream neighbors', domi-nance of Nile basin issues, prone to influxes of refugees (Homer-Dixon and Kelly, 1995).

The Gaza Strip, a $40 \mathrm{~km}$ by $10 \mathrm{~km}$ stretch of land is located on the Mediterranean
Coast of the Middle East where Israel meets the Sinai Peninsula. This 360 sq. $\mathrm{km}$ area of land has $40 \mathrm{~km}$ of coastline, an $11 \mathrm{~km}$ boundary with Egypt, and a $51 \mathrm{~km}$ boundary with Israel. 13\% of the Strip is comprised of arable land, $32 \%$ of permanent crops, and $55 \%$ other usages. $115 \mathrm{sq} . \mathrm{km}$ of this land is irrigated and desertification is currently an important environmental issue (Gaza, 2010).

There are many different types of the disasters, both natural and manmade, which occur in various countries throughout the world. When these disasters occur, an array of management teams is mobilized to properly clean up and manage these disasters; the FEMA (Federal Emergency Management Agency) has specific ways of deal- 
ing with different disasters (Freedman et al, 2006).

Infectious disease disasters are events that involve a biological agent/disease and that result in mass casualties, such as a bioterrorism attack, a pandemic, or an outbreak of an emerging infectious disease, Infections pathogens include some viruses, bacteria, fungi, protozoa, helminthes. These pathogens are the cause of disease epidemics. All disasters pose the risk of the infection transmission, but infectious-disease disasters pose the greatest risk to illness or death from an infectious disease. Infectious-disease disasters pose different challenges for the disaster planners because the nature of the event is different from a traditional disaster. In traditional disasters, there is often the need to relocate victims and provide shelter and care for the displaced individuals. In infectious-disease disasters, displacement of individuals should not be necessary and victims will pose an infectious risk to those around them (Ryan and Ray, 2004).

The University Pittsburgh Medical Center formed the UPMC Bioterrorism Preparedness Group in order to strengthen its already existing ties with federal, state and local law enforcement and public health agencies. The mission of the group is to make sure the quality of patient care is not compromised in the event of a disaster; and to devise systems with the expertise of infectious disease and disaster specialists to ensure that life-saving antidotes and vaccines to bioterrorism agents can be accurately tested and implemented in a timely manner (Cho and Chu, 2013).

Infectious-disease disasters require the implementation of infection prevention strategies such as isolation, quarantine and post-exposure prophylaxis. The large influx of potentially infectious patients during an infectious-disease disaster will put the different kind of strain on medical facilities and require larger-than-usual stocks of personal protective equipment to manage patients safely (CDC, 2010).
Health care facilities should have a disaster plan that addresses all types of hazards, including pandemics and other infectiousdisease disasters. Because dis-asters can have infection control implicat- ions, it is vital that planning involve infection control professionals. So, it is not necessary for all infection control pro-fessionals to be involved in the disaster planning, but each facility should assign one to their facility disaster planning committee. In their role on the planning committee, the infection control professional should provide consultation on preventing infection trans-mission during disasters (Carlson et al, 2010).

In infection spread during a disaster control issues that must be addressed in hospital disaster plans include surveillance, isolation, personal protective equipment use, hand hygiene, quarantine, cleaning and disinfection of the environment, treatment, prophylaxis, vaccination (when available) and postmortem care of victims. Many of these same issues are covered by the facility's infection control program and policies/procedures. However, these policies and procedures will need to be expanded and made more flexible for disasters. For instance, surveillance during a disaster needs to be different than routine surveillance procedures in terms of diseases/conditions tracked by the hospital. Disaster surveillance will include both prevent surveillance to detect an incident and surveillance that occurs during and after the event. Isolation procedures may be required if the disaster involves a communicable disease. In the event of a pandemic, isolation will be vital to reduce the spread of infection from person to person. Adequate stocks of personal protective equipment also need to be available to health care facilities but may be difficult to obtain during an infectiousdisease disaster (Carrier et al, 2012).

The current study spotlights on selected infectious diseases that could be posing a risk of infection transmission to the Egyptian Eastern border. The first selected infectious disease was the Bioterrorism; An- 
thrax, caused by Bacillus anthracis, was an uncommon illness in the United States. From 1980 through 2000, only seven cases of anthrax were reported by CDC (Pan et al, 2013). In 2001, a total of 22 confirmed or suspected cases of bioterrorism-related anthrax occurred in the United States, when $B$. anthracis spores in powder-containing envelopes were sent through the mail.

Subsequent sporadic cases have occurred rarely in the US, such as in individuals exposed to contaminated animal hides while making traditional drums (Guh et al, 2010). The second selected infectious disease was the Relapsing fever, caused by spirochetes of the Borrelia genus, is an arthropod-borne infection, which occurs in two major forms: tick-borne (TBRF) and louse-borne (LBRF): Tick-borne relapsing fever is a zoonosis and is endemic in many countries. The two main Borrelia spp. involved in North America are $B$. hermsii (in the mountainous West) and $B$. turicatae (in the southwest). Other tickborne species cause relapsing fever on other continents (El Babnasawy et al, 2012). The third selected infectious disease was Louseborne relapsing fever caused by B. recurrentis. It is principally a disease seen in the developing world; it is spread from person to person by the body louse and can occur in epidemics, including large ones involving millions of people as the name implies, relapsing fever is characterized by recurrent episodes of fever that accompanies spirochetemia. The disease relapses are due to antigenic variation by the spirochetes (Dworkin et al, 2008). The fourth selected infectious disease was Clonorchis sinensis: C. sinensis are leaf-shaped and hermaphroditic, ranging in size from a few millimeters to several centimeters. The adult flukes allow differentiation of species, although the eggs of these parasites are all yellowishbrown in color, oval in shape, and measure approximately 20 to $30 \mu \mathrm{m}$ by $15 \mu \mathrm{m}$, making species identification difficult. The eggs also resemble those of other intestinal flukes. The adult undergoes asexual repro- duction in snails, which are the intermediate host, and undergo sexual reproduction in definitive mammalian hosts. Man is an accidental host. Different genera of snails and fish serve as the first and second intermediate hosts respectively. The geo-graphical ranges and habitats of these fish and snail species contribute to the geogra- phic distributions of human infection by each of these flukes (Morsy and El-Mathal, 2011).

\section{Rational}

The four infectious disease disasters at Egyptian Eastern Border were selected in the current study due to their epidemiological importance being encountered in Egyptian Eastern Border.

In Egypt, there is less awareness and knowledge about these diseases. 1- Anthrax caused by Bacillus anthracis, which is the most dangerous Bioterrorism worldwide. This disease is a real risky health problem not only to Egypt but also to the regional countries. Anthrax besides, considered as one of the blood-borne diseases, blood sucking arthropods. Unfortunately, these bloodsucking insects are common in Egypt which may play a role as vector of this Bioterrorism disease, spread it among man and animals whether edible or domestic ones. 2Tick borne relapsing fever is transmitted mainly by ticks. In Egypt up to 32 genera and species are reported. 3- Louse borne replasing fever is transmitted by human lice. The three types of lice infesting man are common among preschool and school aged children. Unfortunately, in Egypt, head and body lice have been en-countered among the Pediatric hospitals' patients, House-hold Orphanage children and School-children. 4Clonorchis sinensis, this liver fluke could be easily introduced with imported fish or employees returning back from neighboring countries in the incubation period. One must keep in mind that this parasite utilized many snails and many fishes as first and second intermediate host. Clonorchiasis is currently reported in a family returning back from Saudi Arabia, where the disease is endemic there. 
This study was aiming to raise awareness and improve knowledge by educational program for military nursing staff on the selected infectious disease disasters acquired at Egyptian Eastern Border.

Objective of the study: 1- to implement an educational program for military nursing staff on selected infectious disease disasters at Egyptian Eastern Border, 2- to evaluate the knowledge gained by nursing staff after the educational program, and 3- to design a self-instruction booklet on the four selected infectious disease disasters acquired at the Egyptian Eastern Border (Spotlight on four infectious disease disasters at the Egyptian Eastern Border; National Library and the National Archives; deposit No. 19298 at 1/11/2011).

\section{Results}

The results are shown in tables (1 to 11) and figures (1 to 7).

Table 1: Distribution of nursing staff as regard different age groups $(n=125)$

\begin{tabular}{|c|c|c|c|}
\hline Age (years) & No. & \multicolumn{2}{|c|}{$\%$} \\
\hline Less than 20 & 23 & \multicolumn{2}{|c|}{18.4} \\
\hline-20 & 60 & \multicolumn{2}{|c|}{48.0} \\
\hline-31 & 35 & \multicolumn{2}{|c|}{28.0} \\
\hline More than 40 & 7 & \multicolumn{2}{|c|}{5.6} \\
\hline Descriptive & Mean \pm SD & Range & Median \\
Statistics & $27.8 \pm 7.5$ & $18.0-51.0$ & 27.0 \\
\hline
\end{tabular}

Nurses (48\%) were in the age category 20 30 years with a highly significant difference as regard age categories. Variation assessed relationship between ages and knowledge level, nurses ages ranged from (18-51) with mean ages of $27.8 \pm 7.5$ and median 27.0.

Table 2: Distribution of nursing staff as regard education.

\begin{tabular}{|l|l|l|}
\hline Education & No. & $\%$ \\
\hline Diploma & 100 & 80.0 \\
\hline Technical Institute of nursing & 16 & 12.8 \\
\hline Bachelor Degree & 4 & 3.2 \\
\hline Other & 5 & 4.0 \\
\hline
\end{tabular}

Nurses (80\%) had nursing school diploma, although pre-test intervention was without difference in the knowledge regarding the educational level, yet post-test showed a significant difference between knowledge levels and educational levels.

Table 3: Nurses' opinion regarding previous knowledge suggested program topics.

\begin{tabular}{|l|c|c|c|c|c|c|}
\hline \multirow{2}{*}{ Topics } & \multicolumn{4}{|c|}{ Studied } & \multicolumn{2}{c|}{ Not Studied } \\
\cline { 2 - 5 } & \multicolumn{3}{|c|}{ Sufficiently } & Insufficiently & \multicolumn{2}{c|}{} \\
\cline { 2 - 6 } & No. & $\%$ & No. & $\%$ & No. & $\%$ \\
\hline Definition of infectious diseases. & 44 & 35.2 & 75 & 60.0 & 6 & 4.8 \\
\hline Definition of infectious disease disasters. & 17 & 13.6 & 65 & 52.0 & 43 & 34. \\
\hline Infectious diseases via Egyptian Eastern border & 16 & 12.8 & 29 & 23.2 & 80 & 64.0 \\
\hline Control of infectious disease disasters in hospitals. & 31 & 24.8 & 34 & 27.2 & 60 & 48.0 \\
\hline Role of infection control nurse. & 54 & 43.2 & 33 & 26.4 & 38 & 30.4 \\
\hline How to act upon confirmation of disease presence & 59 & 47.2 & 38 & 30.4 & 28 & 22.4 \\
\hline Notification authority when disease happened & 76 & 60.8 & 30 & 24.0 & 19 & 15.2 \\
\hline
\end{tabular}

The nurses (64\%) knew nothing about Anthrax, TBRF, LBRF, $C$. sinensis introduction via Egyptian Eastern border and
$48 \%$ of them have no idea about the control of infectious disease disasters within the hospitals. 
Table 4: Training status of nursing staff on the educational program.

\begin{tabular}{|l|l|l|}
\hline Nurses' Training Status & No & $\%$ \\
\hline Attendance of training program about infectious diseases & \multicolumn{2}{|l|}{} \\
\hline Yes & 42 & 33.6 \\
\hline No & 83 & 66.4 \\
\hline If yes: • When did you get this program? & 17 & 40.5 \\
\hline More than one year & 25 & 59.5 \\
\hline less than one year
\end{tabular}

Nurses $(66 \%)$ did not attend educational program about infectious diseases, so this study gave them an updating knowledge

Table 5: Nurses willing to attend educational program about infectious diseases disasters

\begin{tabular}{|l|l|l|}
\hline Nurses & No & $\%$ \\
\hline Willing & 125 & 100.0 \\
\hline Not willing & 0 & 0.0 \\
\hline
\end{tabular}

All were willing to attend an educational program on infectious diseases disasters.

Table 6: Nurses' opinion as regard best duration, time and place for educational program

\begin{tabular}{|l|l|l|l|l|l|}
\hline Nurses' Opinion & No. & $\%$ & Nurses' Opinion & No. & $\%$ \\
\hline Best Duration & 21 & 16.8 & Morning Shift & 103 & 82.4 \\
\hline One Week & 30 & 24.0 & After-Noon Shift & 14 & 11.2 \\
\hline Two Weeks & 14 & 11.2 & Night Shift & 8 & 6.4 \\
\hline Three Weeks & 11 & 8.8 & Best Place \\
\hline Month & 49 & 39.2 & Inside Hospital & 42 & 33.6 \\
\hline$>1$ Month & Training center & 83 & 66.4 \\
\hline Best Time
\end{tabular}

Nurses (39.2\%) agreed that $>1$ month was best duration, $82.4 \%$ agreed at morning shift was better, on the other hand, $66.4 \%$ of them preferred a training center.

Table 7: Opinion on how to receive knowledge, appropriate lecture's duration \& presentation

\begin{tabular}{|l|l|l|l|l|l|l|}
\hline Nurses' Opinion & No. & $\%$ & Nurses' Opinion & No. & $\%$ \\
\hline Receiving knowledge by & \multicolumn{5}{|l|}{ Appropriate duration of lectures } \\
\hline Audio only & 0 & 0.0 & From 15-30 min & 25 & 20.0 \\
\hline Visual & 11 & 8.8 & From 30-45 min & 50 & 40.0 \\
\hline Audiovisual & 65 & 52.0 & From 45-60 min & 32 & 25.6 \\
\hline Visual / participation & 49 & 39.2 & $>1$ hour & 18 & 14.4 \\
\hline \multicolumn{2}{|c|}{ Presentation types } & & & \\
\hline Individual & 3 & 2.4 & & & \\
\hline Group & 68 & 54.4 & & & \\
\hline Both & 54 & 43.2 & & & \\
\hline
\end{tabular}

Nurses $(52.0 \%)$ preferred the audiovisual method of teaching, $54.4 \%$ preferred group presentation and $40.0 \%$ preferred $30-45 \mathrm{~min}$. for lecture duration. 
Table 8: Nursing staff knowledge levels as regards topics in pre and post-test.

\begin{tabular}{|l|l|l|l|l|l|l|l|}
\hline \multirow{2}{*}{ Items } & \multicolumn{2}{|l|}{ Pre-intervention } & \multicolumn{2}{l|}{ Post1-Intervention } & \multicolumn{2}{l|}{ Post2-Intervention } & P- Value \\
\cline { 2 - 8 } & Median & Range & Median & Range & Median & Range & \\
\hline Anthrax & $3 \mathrm{a}$ & $0-7$ & $8 \mathrm{~b}$ & $5-10$ & $9 \mathrm{c}$ & $7-10$ & $<0.001$ \\
\hline Tick-borne relapsing fever & $2 \mathrm{a}$ & $0-5$ & $4 \mathrm{~b}$ & $0-5$ & $5 \mathrm{c}$ & $3-5$ & $<0.001$ \\
\hline Lice-borne relapsing fever & $2 \mathrm{a}$ & $0-5$ & $4 \mathrm{~b}$ & $2-5$ & $5 \mathrm{c}$ & $4-5$ & $<0.001$ \\
\hline Clonorchis sinensis & $4 \mathrm{a}$ & $0-8$ & $9 \mathrm{~b}$ & $4-10$ & $9 \mathrm{~b}$ & $7-10$ & $<0.001$ \\
\hline Total & $11 \mathrm{a}$ & $2-21$ & $24 \mathrm{~b}$ & $14-30$ & $28 \mathrm{c}$ & $23-30$ & $<0.001$ \\
\hline
\end{tabular}

Median scores of nurses' knowledge about anthrax, tick-and lice-borne relapsing fever, and $C$. sinensis in the pre-intervention, first post-intervention, and the second post inter- vention showed high significant difference $(\mathrm{p}<0.001)$, indicating that their significant knowledge improvement by time.

Table 9: Evaluation of training materials/teaching aids.

\begin{tabular}{|c|c|c|c|c|c|c|c|c|c|c|}
\hline \multirow{2}{*}{$\begin{array}{l}\text { Training materials/Teaching } \\
\text { Aids }\end{array}$} & \multicolumn{2}{|c|}{ Excellent } & \multicolumn{2}{|c|}{ Very Good } & \multicolumn{2}{|c|}{ Good } & \multicolumn{2}{|c|}{ Fair } & \multicolumn{2}{|c|}{$\mathrm{Bad}$} \\
\hline & No. & $\%$ & No & $\%$ & No. & $\%$ & No. & $\%$ & No. & $\%$ \\
\hline Visual / Hearing & 107 & 85. & 18 & 14.4 & 0.0 & 0.0 & 0.0 & 0.0 & 0.0 & 0.0 \\
\hline Hand-out Scientific material & 88 & 70.4 & 35 & 28.0 & 2 & 1.6 & 0.0 & 0.0 & 0.0 & 0.0 \\
\hline
\end{tabular}

Nurses $(86 \%)$ preferred the visual and $70 \%$ of them considered the hand-out of scihearing as excellent training materials and entific material an excellent teaching aids.

Table10 duration.: Evaluation of lecture

\begin{tabular}{|c|c|c|c|c|c|c|}
\hline \multirow[t]{2}{*}{ Lecture duration } & \multicolumn{2}{|c|}{ Too long } & \multicolumn{2}{|c|}{ Suitable } & \multicolumn{2}{|c|}{$\begin{array}{l}\text { Too } \\
\text { short }\end{array}$} \\
\hline & No & $\%$ & No. & $\%$ & & $\%$ \\
\hline Specified Lecture duration allowed group discussion & 36 & 28.8 & 85 & 68.0 & 4 & 3.2 \\
\hline Time specified for replying to questions adequate & 40 & 32.0 & 77 & 61.6 & 8 & 6.4 \\
\hline Generally, how could you find lecture duration? & 77 & 61.6 & 47 & 37.6 & 1 & 0.8 \\
\hline
\end{tabular}

Nurses (68\%) considered specified lecture

and $62 \%$ found time specified for replying to duration allowing group discussion suitable questions was adequate.

Table 11: Evaluation of subject matter.

\begin{tabular}{|l|l|l|l|l|l|r|}
\hline \multirow{2}{*}{$\begin{array}{l}\text { Program Evaluation } \\
\text { subject }\end{array}$} & \multicolumn{2}{|l|}{ Too complicated } & \multicolumn{2}{|l|}{ suitable } & \multicolumn{2}{l|}{ Too simple } \\
\cline { 2 - 7 } & No. & \multicolumn{2}{|c|}{ No. } & No. & $\%$ \\
\hline Subject matter & 4 & 3.2 & 120 & 96.0 & 1 & 0.8 \\
\hline
\end{tabular}

Nurses $96 \%$ considered subject matter suitable.

\section{Discussion}

The results revealed that, more than half of the participants were lying in the age category $20-30$ years (48\%); In addition there was a highly significant difference between participants as regard their age categories, this variation of age groups in this study was important to assess the relationship between the age and different knowledge level, as age of the participants ranged from (18-51) and the mean for participants' ages was $(27.8 \pm 7.5)$ and median was (27.0).

Regarding work department, $31 \%$ of the nurses were from operation departments,
$19 \%$ were from medical departments, $15 \%$ were from surgical departments, $12 \%$ were from Emergency department and 10\% were from intensive care unit. As to level of education $80 \%$ had nursing school diploma, $13 \%$ technical institute of nursing, $3 \%$ bachelor degree and $4 \%$ others. Although in the pre test intervention there was no difference in the knowledge about the study, yet in the post test there was a significant difference between the levels of knowledge among the four educational levels.

Regarding years of experience, $36.8 \%$ were less than $5 y$ work experience, $27.2 \%$ 
were $5-10 \mathrm{y}, 16.8 \%$ were $10-15 \mathrm{y}, 8.8 \%$ were $16-20 \mathrm{y}$ and $10.4 \%$ were more than 20years. Their work experience ranged from less than $5 \mathrm{y}$ to more than $20 \mathrm{y}$. So, there was a positive impact as the more the years of experience, the more the level of knowledge of the participants.

As regarding the past experience of studying about $64 \%$ of the studied participants know nothing about the selected Infectious diseases transmitted through the Egyptian Eastern border (Anthrax, TBRF, LBRF, Clonorchis sinensis) more than that about $48 \%$ have no idea about the Control of infectious disease disasters at hospitals.

About $66 \%$ of the participating nurses not attending any training program about infectious diseases, so that the target of this study was to give them an updating knowledge about infectious diseases, infectious diseases disaster, and infectious diseases disaster prevention. About $87 \%$ of the participants were attending a Program about infection control mostly for 2 weeks.

Since more than 1 year, $70 \%$ of this group have a knowledge about how to control an infectious diseases, although they do not cope with the knowledge about the infectious diseases disaster control in the pre test, only $23 \%$ of the participating nurses attending training program about Nursing emergencies and disasters so in the pre test the evaluation of their knowledge about this subject was very minimal, the most of the attendants $98 \%$, found the program useful.

The results agreed with Frankel (2008) who reported the nurse leaders must demonstrate resilience in responding to change and supporting others to embrace this in a positive way. Effective leaders should be capable of reframing the thinking of those whom they are leading, enable them to see the changes are not only imperative but achievable. So, it was recommended in this study that leaders showed more care and encouragement for nurse training.
In this study, all the participants were willing to attend an educational program about infectious diseases disasters to increase their knowledge as regard infectious disease disasters at Egyptian Eastern Border and to know Prevention and control about infectious diseases. This agreed with Dyson et al. (2009) showed that education for nurses was not always systematically planned and developed and often relied on the interest area and assessment of the nurse educators. Also, WHO (2009) found that all of the nurses in study know how to prevent the infectious diseases and stated that nurses form the back bone of the health systems of all countries in the developing world and have a major contribution to make in attaining the Millennium Development Goals. They also have the greatest contact with service users, and are therefore the greatest potential for both prevention education and bridging the health service and community gap. Arnold (2013) stated that "We do not want a two-tier nursing workforce. Instead, we need to do more on the education, training and regulation of healthcare assistants".

Nurses in infectious disease disasters have an important role to play in giving health education to the community. They should teach people to seek medical help promptly whenever a family member is sick to get early diagnosis and correct treatment and academic medical centers can play an important role in disaster response (Ripp et al, 2012).

There was significant improvement in the nurse's staff total knowledge score in posttest as compared to that in pre-test. Training is systemic development of the knowledge, skills, and expertise required by a person to effectively perform a given task or job. Liang et al. (2013) found that nursing assistants with higher scores for job control and work-related social support tend to enjoy better mental health, as indicated by higher mental component summary scores and that reducing selected job stressors and enhanc- 
ing job control to improve nursing assistants' health-related quality of life.

As regard different studied topics in pre and post test in infectious disease disaster at Egyptian Eastern Border, there was high significant difference $(p<0.001)$, indicating significant improvement of their knowledge over time. Meanwhile, in the post-test phase, knowledge had improved and majority of the participants gave the correct answer, and retained the knowledge after three months, additionally, the foregoing present study findings related to improvements in nursing staff knowledge after the program implementation reflects success of educational program the median scores of nurses' knowledge about anthrax, tick-borne relapsing fever, lice-borne relapsing fever, and $C$. sinensis indicated statistically significant improvement $(p<0.001)$, in nursing staff knowledge (includes recall or recognition of facts, procedural patterns, and concepts that serve in the development of intellectual abilities and skills an intellectual skill is gained during a course of study) comparing the preintervention, post1-intervention, and post2intervention results.

These results agreed with many previous studies that had demonstrated a positive effect and high improvement of educational programs on subject's knowledge (O'Connell et al, 2004; Singer et al, 2009). Reinders et al. (2011) studied the effect of patient feedback interventions as a method of improving physicians' consultation, found that some evidence for the effectiveness of using feedback from the real patients to improve the knowledge and behavior exists; however, before implementing patient feedback into training programs, educators and policy makers should realize that the evidence for effecting actual improvement in physicians' consulting skills is rather limited.

Peterson et al. (2012) reported the need for perinatal unit-level interventions to support the development of nurses' skills in caring for adolescent mothers and their knowledge of community-based resources. Peer mentor- ing and self-reflective practice are promising strategies. Tang and Dong (2013) reported that the positive outcomes of this program support the idea that mastery learning is an effective competency-based training method for clinical skills acquisition. However, variations in training duration and dropout rates should be taken into consideration when planning mastery learning-based training programs. Moreover, Zainy et al. (2013) stated that the level of knowledge among parents of epileptic children needed to improve the quality of life of these families.

In the present study, the use of a continuous education program had successfully influenced nursing knowledge, this in service education program turned to be effective in increasing the level of the nurses' knowledge regarding infectious disease disaster at Egyptian Eastern Border, regardless their basic educational preparation. Mean scores on the assessment test were $84 \%$ at baseline and $89 \%$ following the educational program. Therefore, the use of a continuing education program in present study had successfully influenced nursing knowledge, this in service education program turned to be effective in increasing the level of nurses' knowledge regarding infectious disease disaster at Egyptian Eastern Border, regardless their basic educational preparation. Boerner and Dütschke (2008) mentioned that to face organizations in the health care sector extensive management initiatives that foster employees' commitment to and support for organizational change are needed in hospitals. First to investigate the positive impact that charismatic leaders have on followers' initiative-oriented behavior in the hospital, not only to provide professional training but also to intensify efforts in training specialized on charismatic leadership. Second, to support followers' participation in change processes, hospital managers should consider if and how the degree of followers' job autonomy can be enhanced. Alpert et al. (2013) concluded that nursing programs planning to undertake accelerated programs to transition 
medical doctors to nurse practitioners should consider they retake courses such as physical assessment, pharmacology and pathophysiology.

In the present study, evaluation of the tutor of the program from the participant opinion was excellent in general. The tutor gave the good teaching skills and communication capabilities (93\%), the tutor competence with the scientific curriculum (94\%) and gave a good example on teaching $(94.4 \%)$. Nurses (86\%) evaluated visual and hearing as an excellent training materials/teaching aids and $(70 \%)$ recommended distribution of notes containing the scientific material as an excellent teaching aids. Veenema (2006) found that satisfaction with training and development was a major factor in decisions regarding people careers. Cohen (2009) reported that goal-directed behavior can be thought of as dynamic links between sensory stimuli and motor acts suggest that the lateral intraparietal area contains a modalitydependent representation that is highly dependent on behavioral context. FernándezSola et al. (2013) suggested a need to support and guide clinical tutors, to increase coordination between the university and health services, to organize the students' theoretical and practical training and to provide the management of the model with flexibility and transparency

In the present study, nurses (68\%) considered the specified lecture duration allowing group discussion was suitable and $(62 \%)$ found that the time specified for replying to trainee's questions was adequate. As to the place, nurses $(49 \%)$ found that the training room was excellently well equipped and clean, $(56 \%)$ found that supplying the training room with computer devices was very good, $(60 \%)$ found that generally the training room was very good, and (96\%) considered the subject matters suitable. Trainees' expectations (74\%) agreed that the educational program met their expectations, $(61 \%)$ agreed that each topic was well identified and followed, while only (55\%) would be able to apply the knowledge learned, (60\%) agreed that the sessions' content was organized \& easy to follow, (64\%) found the trainer met the educational objectives, $(66 \%)$ found the quality of instruction was good, (70\%) agreed that the trainer had achieved its educational objectives, $(73 \%)$ found that the class participation and interaction were encouraging, while (78\%) agreed that an adequate time was provided for questions and discussion.

Sangster-Gormley et al. (2013) declared that the number of people living longer is increasing, and those with physical or cognitive impairments may need admission into long-term care settings. In long-term care there is a need to increase nursing staff's capacity to meet the care needs of residents, develop a team approach to providing care and provide opportunities for staff to improve their knowledge and skills. One approach to meet these needs has been to employ a nurse practitioner (NP) in long-term care settings. Evans and Kohl (2013) stated that as an emergency nurse, finding time to familiarize oneself with arterial-line monitoring or a new piece of equipment is often impossible. A group of staff nurses recognized the need for more "hands-on" learning and pursued a method to make their education more meaningful. A hospital general nursing skills day offered little benefit to educate nursing staff who are tasked with more specialized skills. It was imperative to develop an efficient process to prepare the ED nurses to provide best practice and care to their patients.

Stone et al. (2013) reported that care home staff needs to develop the knowledge, skills, and confidence to engage in discussions around end-of-life care. The assistance of a trained facilitator who role-models this process should be explored. Riley and Beal (2013 went deep to the fact by declaring that although clinical scholarship is an espoused professional ideal, how nurses develop and maintain a scholarly approach to nursing practice throughout different stages 
of their careers was not well understood. They described early-career nurses' accounts of pursuing professional practice as a scholarly endeavor and concluded that nursing needs requires a new scholarly practice development paradigm for a multistage career beginning with a concerted focus on the critical first stage of practice.

Hope et al. (2013) stated that development of practice guidelines should take into consideration the opinions of end users. The Society of American Gastrointestinal and Endoscopic Surgeons (SAGES) have implemented several changes in its guideline development and dissemination process based on previous end-user input.

Handley and Dodge (2013) added that when looking to generate financial support to develop simulation practices within education, little evidence existed regarding its impact within clinical practice. They found that overwhelming support for simulated learning from students and facilitators. But, without clear guidance or strategies universally used to effectively incorporate simulation within nurses' curricula, nor to evaluate or audit its effect upon student competency within clinical practice. Further evidence to support the implementation of simulation within nurse education is therefore required to ensure effective implementation and transferability of learning into clinical care

\section{Conclusion}

From the outcome results of this study, the implementation of the educational program for Military Nursing Staff on selected infectious disease disasters at Egyptian Eastern Border was effective.

Given the fact that all the participants were willing to attend an educational program about infectious diseases disasters

In the studied settings, the intervention showed statistically significant improvements in nursing staff knowledge, these improvements were observed at the immediate post intervention phase, and were retained throughout the after three months post-test phase, the study has also indicated statistically significant strong positive correlations among staff nurse knowledge and scores, multivariate analysis has revealed that Nursing Staff knowledge were positive.

Hence, it is expected that this improvement in nursing staff knowledge would have a positive impact on the dealing with infectious disease, infectious disease disaster prevention and control and more professional dealing with different emergencies and disasters.

The selected four infectious were selected based on the fact that they may be in one way or another is introduction into Egypt.

If one considered Anthrax it can be transmitted by different routes including the blood sucking Arthropod mainly Tabanus species and Chrysops species. Both are reported in Egypt. Tick borne relapsing fever is transmitted by both soft and hard ticks. As many as 32 genera of ticks are encountered in Egypt. Also, louse borne relapsing fever is transmitted by lice. In Egypt, lice infestations have been reported in different human class levels.

As to Clonorchis sinensis, this hepatic fluke is one of the main causes of carcinogenesis. The point is that this parasite can used any snail as the first intermediate host and any fish as second intermediate host.

Consequently, the outcome results clarify the public health problems of these parasites, and learning them to the Staff Nurses will improve their health knowledge.

\section{Recommendations}

In the light of the study findings, the following recommendations will be provided for improving Nursing staff knowledge, skills and future researcher.

1- In service training programs about infectious disease disasters at Egyptian Eastern Border must be developed and provided on regular basis. This would enable nursing 
staff to improve their knowledge about infectious disease disasters.

2- Orientation program must be designed to raise awareness and improve knowledge for newly nursing staff.

3- Allow opportunities for nursing staff to attend training programs.

4- Establish staff development department center in the organization responsible for upgrading and improving nurses' level.

5- Establish library related to nursing science in each organization which sustains Textbooks, Magazines Journals and Bulletins that can improve different categories of nursing personal knowledge and performance.

6- Design a self-instruction booklet on selected infectious disease disasters acquired at Egyptian Eastern Border.

7- Adapt a well-designed plan to provide an efficient systematic response to any type of disaster or emergency.

8 - Since the world is now one big village, an emerging disasters nurse or preventive disasters nurse on call could be a must.

\section{References}

Alpert, PT, Yucha, CB, Atienza, M, 2013: An advanced practice nursing program for foreign medical doctors: a practical approach. Nurs. Educ. Perspect. 34, 4:254-9.

Arnold, U, 2013: Patients would benefit from having two types of nurses. Nurs Sta-nd. 28, 15:32.doi:10.7748/ns2013.2.28.15. 32.s43.

Boerner, S, Dütschke, E, 2008: The impact of charismatic leadership on followers' initiativeoriented behavior: a study in German hospitals. Hlth. Care Manag. Rev. 33, 4:332-40.

Carlson, AL, Budd, AP, Perl, TM, 2010: Control of influenza in healthcare settings: early lessons from the 2009 pandemic. Curr. Opin. Infect. Dis. 23, 4:293-9.

Carrier, E, Yee, T, Cross, D, Samuel, D, 2012: Emergency preparedness and community coalitions: Opportunities and challenges. Res. Brief. 24:1-9.

CDC, 2010: Rapid establishment of an internally displaced persons' disease surveillance sys- tem after an earthquake-Haiti. MMWR Morb Mortal Wkly Rep. 59, 30: 939-45.

Cho, HW, Chu, C, 2013: How to manage a public health crisis and bioterrorism in Korea. Osong. Pub. Hlth. Res. Perspect. 5:223-4

Cohen, YE, 2009: Multimodal activity in the parietal cortex. Hear Res. 258, 1/2:100-5.

Dworkin, MS, Schwan, TG, Anderson, DE, Borchardt, SM, 2008: Tick-borne rela- psing fever. Infect. Dis. Clin. North. Am. 22: 449-54.

Dyson, L, Hedgecock, B, Tomkins, S, Cooke, G, 2009: Learning needs assessment for registered nurses in two large acute care hospitals in Urban New Zealand. Nurse Educat. Today 29, 8:821-8.

El-Bahnsawy, MM, Labib, NA, Abdel-Fattah, MA, Ibrahim, AM, Morsy, TA, 2012: Louse and tick-borne relapsing fevers. J. Egypt. Soc. Parasitol. 42, 3:625-38.

Evans, L, Kohl, D, 2013: Mission Impossible? Educating an Emergency Nurse. J. Emerg. Nurs. May 22. pii: S0099-1767(13) 00106-2.

Fernández-Sola, C, Granero-Molina, J, Márquez-Membrive, J, Aguilera-Manriq- ue, G, Castro-Sánchez, AM, 2013: Imple- mentation of the new clinical practice training model in Andalusia: A qualitative evaluation of the Nursing and Physiotherapy degrees. Enferm. Clin. Nov 19. pii: S1130-8621(13)00151-4.

Frankel, A, 2008: What leadership styles should senior nurses develop? This is an extended version of the article published in Nursing Times 104, 35:23-4.

Freedman, DO, Weld, LH, Kozarsky, PE, et al. 2006: Spectrum of disease and relation to place of exposure among ill returned travelers. N. Engl. J. Med. 354:119.

Gaza Strip, 2010: Palestine and the Palestinians: Profile. About.com

Guh, A, Heyman, ML, Barden, D, Fonta- na, J, Hadler, JL, 2010: Lessons learned from the investigation of a cluster of cutaneous anthrax cases in Connecticut. J. Publ. Hlth. Manag. Pract. 16, 3:201-10

Handley, R, Dodge, N, 2013: Can simulated practice learning improve clinical competence? Br. J. Nurs. 22, 9:529-35.

Homer-Dixon, T, Kimberley, K. 1995: Environmental Scarcity and Violent Conflict: The Case of Gaza, Project on Environment, Popula- 
tion and Security: American Association for the Advancement of Science and the University of Toronto.

Hope, WW, Richardson, W, Fanelli, R, Stefanidis, D, 2013: How do SAGES members rate its guidelines? Surg Endosc. Nov 7.

[Epub ahead of print]

Liang, YW, Hsieh, Y, Lin, YH, Chen, W Y, 2013: The impact of job stressors on healthrelated quality of life of nursing assistants in long-term care settings. Geriatr. Nurs. Nov 19. pii: S0197-4572 (13)00392-3.

Morsy, ATA, Al-Mathal, EM, 2011: Clonorchis sinensis: A new report in Egyptian employees returning back from Saudi Arabia. J. Egypt. Soc. Parasitol. 41, 1:219-22.

O'Connell, MT, Rivo, ML, Mechaber, AJ, Weiss, BA, 2004: A curriculum in systemsbased care: experiential learning changes in student knowledge and attitudes. Fam. Med. 36:S99-104.

Pan, Y, Rose, CE, Haber, M, Ma, Y, Carrasco, JL, et al, 2013: Assessing agreement of repeated binary measurements with an application to the CDC's anthrax vaccine clinical trial. Int. J. Biostat. 29, 1:1-8.

Peterson, WE, Davies, B, Rashotte, J, Salvador, A, Trépanier, MJ, 2012: Hospital-based perinatal nurses identify the need to improve nursing care of adolescent mothers. J. Obstet. Gynecol. Neonat. Nurs. 41, 3:358- 68.

Rao, PV, Rao, SL, Vijayakrishnan, B, Chaudhary, AB, Peril, S, et al, 2007: Know-ledge, attitude and practices about leprosy among medical officers of Hyderabad urban district of Andhra Pradesh. Indian J. Lepr. 79, 1:27-43.

Reinders, ME, Ryan, BL, Blankenstein, A H, van der Horst, HE, Stewart, MA, et al, 2011: The effect of patient feedback on physicians' consultation skills: a systematic review. Acad. Med. 86, 11:1426-36.
Riley, JM, Beal, JA, 2013: Scholarly nursing practice from the perspectives of early-career nurses. Nurs. Outlook. 61, 2:e16-24.

Ripp, JA, Bork, J, Koncicki, H, Asgary, R, 2012: The response of academic medical centers to the 2010 Haiti earthquake: the Mount Sinai School of Medicine experience. Am. J. Trop. Med. Hyg. 86, 1: 32-5.

Ryan, KJ, Ray, CG. 2004: Sherris Medical Microbiology $4^{\text {th }}$ edition McGraw Hill.

Sangster-Gormley, E, Carter, N, Donald, F, Misener, RM, Ploeg, J, et al, 2013: A valueadded benefit of nurse practitioners in long-term care settings: increased nursing staff's ability to care for residents. Nurs. Leadersh (Toronto). 26, 3:24-37.

Singer, Y, Carmel, S, 2009: Teaching end-oflife care to family medicine residents-what do they learn? Med. Teach. 31, 2:e47-50.

Stone, L, Kinley, J, Hockley, J, 2013: Advance care planning in care homes: the experience of staff, residents, and family members. Int. J. Palliat. Nurs. 19, 11:550-7.

Tang, WE, Dong, L, 2013: Applying mastery learning in a clinical skills training program for primary care nurses. J. Contin. Educ. Nurs. 44, 12:535-41.

Veenema, TG, 2006: Early Detection and Surveillance for Bio-preparedness and Eme-rging Infectious Diseases. Online J. Issues Nurs. Kent State University College of Nur-sing: www. pubmed central. nih.gov

WHO, 2009: Diseases covered by NTD department. Retrieved from http://www. who. int/neglected diseases/ diseases/en/

Zainy, LE, Atteyah, DM, Aldisi, WM, Abdulkarim, HA, Alhelo, RF, et al, 2013: Parents' knowledge and attitudes toward children with epilepsy. Neurosciences (Riyadh). 18, 4:345-8. 


\section{Explanation of figures}

Figure 1: Distribution of nursing staff as regard work department (Nurses (31\%) were from operation departments, $19 \%$ were from medical departments and $15 \%$ were from surgical departments, and $12 \%$ were from emergency department and $9.6 \%$ were from intensive care unit.

Figure 2: Distribution of nursing staff as regard years of experience. Nurses $(36.8 \%)$ were $<5$ y experience, $27.2 \%$ were $5-10 \mathrm{y}$ experience, $16.8 \%$ were $10-15 \mathrm{y}, 8.8 \%$ were $16-20 \mathrm{y}$ and $10.4 \%$ were $>20 \mathrm{y}$ experience. Working experience ranged from $<5 \mathrm{y}$ to more than $20 \mathrm{y}$, with a positive impact between increased years of experience, and increased of knowledge levels.

Figure 3: Duration of attended program

Figure 4: Nursing Staff opinion regarding attending program about infectious diseases disasters. Nurses $(87 \%)$ attended program on infection control for 2 weeks; and $70 \%$ for more than 1 year, (of this group have acknowledge about how to control an infectious diseases, although they do not cope with the knowledge about the infectious diseases disaster control in pre-test. Nurses (98\%) considered the program useful.

Figure 5: Tutor evaluation Tutor of program proved capabilities (93\%), tutor competence with scientific curriculum (94\%) and a good teaching method (94.4\%).

Figure 6: Evaluation of Place of Training Nurses (49\%) found that training room very well-equipped and clean, $56 \%$ found that supplying training room with computer devices very good and $60 \%$ found that training room very good.

Figure 7: Trainees' expectations in relation to the received educational program Nurses (74\%) agreed that educational program met with their expectations, $(61 \%)$ agreed that educational objectives for each topic was well identified and followed, while only (55\%) would be able to apply knowledge learned, $(60 \%)$ agreed that sessions' content were organized \& easy to follow, $(64 \%)$ met educational objectives, $(66 \%)$ found quality of the instruction was good, (70\%) had achieved educational objectives, $(73 \%)$ found that class participation and interaction were encouraged, while (78\%) agreed that an adequate time was provided for questions and discussion. 

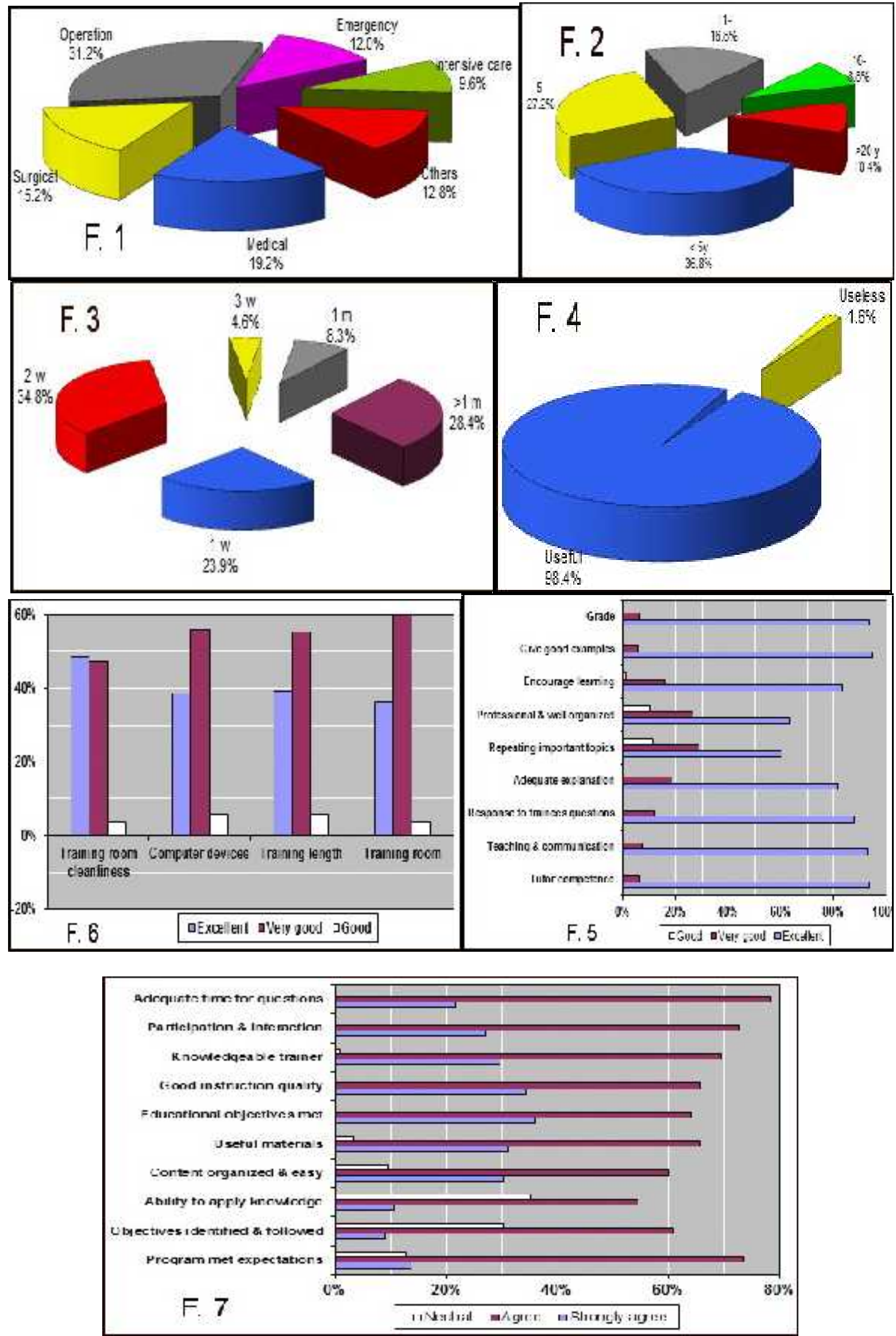